\title{
Scale-dependent variability of density estimates and morphometric relationships in subtidal stands of the kelp Lessonia trabeculata in northern and central Chile
}

\author{
Patricio A. Camus, F. Patricio Ojeda \\ Departamento de Ecología, Facultad de Ciencias Biológicas, P. Universidad Católica de Chile, Casilla 114-D, Santiago, Chile
}

\begin{abstract}
Several morphological parameters, and estimates of density and evenness per depth, were analyzed for stands of the subtidal kelp Lessonia trabeculata Villouta et Santelices from 2 zones, central and northern Chile. Two sites in each zone were sampled for $2 \mathrm{yr}$, and variability patterns were statistically described using site or zone as classification factors. Bathymetric profiles of density showed a strong qualitative and quantitative variation among sites, contrasting with the high evenness in spatial distribution of plants per depth interval, despite intervals of varying length. Relationships among morphometric parameters changed markedly across spatial scales, producing a high variance in biomass predictions. In most cases, strong site- and zone-specific components were identified, which account for the variability in morphology at both spatial scales. Zone effects may mirror water motion and temperature regimes, among other factors, and site effects may be related to specific habitat configurations. These results show that extrapolation from structural features of single stands for characterizing species may result in misleading inferences. The detection of scale-dependent patterns proved to be a useful starting point for comparative studies of population structure, and necessary before attempting generalizations.
\end{abstract}

\section{INTRODUCTION}

The kelp Lessonia trabeculata Villouta et Santelices is an endemic species from the Chilean coast, occurring from $23^{\circ} \mathrm{S}$ (Antofagasta) to $40^{\circ} \mathrm{S}$ (Osorno) (Villouta \& Santelices 1984). This alga forms dense subtidal stands that extend to $20 \mathrm{~m}$ depth, with individuals more than $2 \mathrm{~m}$ tall, and is the most important brown alga in cover and biomass along the Chilean coast (Vásquez 1991).

Lessonia trabeculata is a recently described species (Villouta \& Santelices 1986), and little is known about its standing stock, dynamics, or demography. Prior studies dealing with estimations of density and biomass (e.g. Villouta \& Santelices 1984) have used morphometric relationships as a tool for predicting individual biomass, and have focused on a single parameter as the best predictor of plant biomass to facilitate field measurements. Such an approach has been pointed out by Santelices (1982) as being the first step for studying natural populations of macroalgae, and as an essential tool for establishing management strategies and for characterizing plants from different ecological environ- ments. However, these studies were done only in 1 or 2 localities in central Chile under similar low-exposure conditions. Consequently there was no evidence concerning how these relationships might vary among sites, and if potential variation could be related to different environmental features, local topography, or structural characteristics at a given site. Vásquez (1991) recently evaluated some morphometric relationships for this species in an exposed environment in central Chile, concluding that only limited comparisons among different studies can be made because morphological attributes are constrained by local physical factors, particularly water motion regime.

The dependence of biological attributes or community organization of subtidal algal stands on local habitat conditions has been reviewed by Schiel \& Foster (1986) and Dayton (1985a), among others, considering factors such as depth, substratum characteristics, water motion, and other physical variables (temperature, light, etc.). It is likely that within-stand distribution of biomass and abundance may be significantly affected by site-dependent features. These effects might be 
detected when comparing different local stands, where variability components may be associated with some meaningful factor or combinations of factors. Such a correlational approach is useful for detecting scalespecific constraints limiting the interpretations or predictions obtained in a particular ecological study (e.g. apparent geographical trends or gradients in community structure), or for overcoming the lack of generality when results are extrapolated to larger spatial scales. This last problem raises the issue of classic reductionism (see e.g. Allen \& Starr 1982, Wiens 1989), which in the context of this work may be related to the aggregation problem (Rastetter et al. 1992), namely the risk of subsuming variance from small- to large-scale components assuming linear relationships.

In this paper we examine differences in morphology and density among 4 natural stands of Lessonia trabeculata in northern and central Chile. Stands in northern Chile are in part the remains of larger ones that were severely disturbed during the 1982-83 El Niño event (I. Kong pers. comm. 1988). In contrast, stands in central Chile were not so disturbed (no 'unusual' mortality was reported during that event). However, it is not the goal of this study to investigate long-term effects of El Niño. Instead, we aim to evaluate how the interpretation of variability arising from measurements or descriptors commonly used for characterizing stands may change at different levels of resolution or scales. We show for these stands that the main sources of variance are not the same at different levels, and general assumptions based on local biological features have little (if any) support. Additionally, this approach allows us to explore possible environmental constraints on kelp morphology or density due to the warmer nature of the northern coastal system and the more sheltered placement of the northern stands as compared to the central ones.

\section{METHODS}

Study sites. Sites in northern Chile were located at Antofagasta $\left(23^{\circ} 26^{\prime} \mathrm{S}\right)$, Península de Mejillones, in a natural bay protected by the presence of Isla Santa María, which is located in the entrance of the bay and acts as a large breakwater generating a sheltered environment. Within this bay, one site was located on the peninsular inshore coast, Caleta Errázuriz (hereafter CE), and the other $2 \mathrm{~km}$ away on the facing coast of Isla Santa María (ISM). ISM has a more even topography, less steep slopes, and comparatively less water motion than CE since it mainly receives waves diffracted from island extremes. No other major difference between sites was apparent. Both sites are dominated by Lessonia trabeculata, although it is possible to find isolated stands of Macrocystis integrifolia some hundred meters apart. Communities in L. trabeculata stands appear bistratified due to the presence of patches of dense turfs of Glossophora, Chondrus, Ulva, Halopteris and Asparagopsis. These plants are however not true understory vegetation, because their cover extends both within and between stands.

In central Chile, the 2 sites were $25 \mathrm{~km}$ apart, being in general more exposed, with greater water motion, and with steeper slopes than the northern sites. Punta de Tralca ( $33^{\circ} 25^{\prime} \mathrm{S}$; hereafter PT) and Quintay ( $33^{\circ} 11^{\prime}$ $\left.\mathrm{S}_{\text {; }} \mathrm{QU}\right)$ have dense stands of Lessonia trabeculata, but both lack the extensive 'understory' algal cover found in the north. Instead, the associated vegetation is very sparse and clumped, composed primarily of Glossophora, Plocamium, and encrusting coralline algae. The patterns observed in both zones are different from those of northern hemisphere or southern Chile kelp forests, where severai kelp species are present (Santelices \& Ojeda 1984, Vásquez 1990) and stands may be multistratified (Villouta \& Santelices 1984). Consequently, no comparisons with those systems will be made.

Sampling. The 4 sites were sampled sporadically from May 1990 to December 1991, mainly due to aperiodic storms, and data from different sampling dates were pooled for each site, thus averaging possible effects due to temporal variation in our spatiallybased results. There are no antecedents for seasonal fluctuations or inter-annual variability in populations of Lessonia trabeculata. A different temporal phenology in central and northern populations would imply a high intra-regional variability, which would be transferred to sites at a lower level and could introduce biases in our measurements, because of the discontinuous nature of our sampling. Such a differential phenology has been observed in populations of the intertidal kelp Lessonia nigrescens (Camus et al. unpubl.). A total of 5 samples for northern sites (ISM and CE) and 4 samples for central ones (PT and QU) were obtained. In each of these samples, individual plants were randomly removed using SCUBA, and their wet biomass, number of stipes per holdfast, maximum plant length (from holdfast to end of the longest frond), and maximum holdfast diameter measured. In addition, line transects (3 for CE, ISM and PT, and 2 for QU) were placed perpendicular to the shoreline, their length corresponding to the total extent of each stand. From these transects we obtained 2 kinds of density estimates. First, the number of plants lying immediately beside the line (within $0.5 \mathrm{~m}$ ) was counted along each transect at $1 \mathrm{~m}$ depth intervals. Second, the number of plants per linear meter, the quotient between the total number of plants per depth interval and the total length of the transect line within each depth interval, was also 
determined. The first measurement is referred to in the text as the density profile. The second measurement also reflects evenness in plant spatial distribution among depth intervals, and therefore is referred to in the text as the evenness profile.

Sample size for morphometric parameters was based on the maximum sample size available for QU, the site with the lowest sampling intensity in time. Sample size for the other sites was adjusted by random selection from the total sample.

We considered 3 levels of observation for the analysis. First, an overall level where the variables for all sites were pooled in a single set for obtaining global descriptive measures. Second, a zone level which pooled variables from northern and central Chile sites separately. Third, a site level where variables for each individual stand were considered separately. We refer in the text to site as a study level, and stand as the study units. Methods included analyses of variance, productmoment correlations, stepwise regression, and discriminant and principal components analysis (Statgraphics 1988). Although multivariate methods are mainly descriptive, they were a useful tool for pattern discrimination. Logarithmic $\left(\log _{10}\right)$ transformations were done when criteria of linearity and normality were not met by a given set of variables. Scheffe tests were used in ANOVA designs when a posteriori multiple means comparisons were required.

Statistical methods were mainly used for pattern detection rather than for hypothesis testing. We did not aim to evaluate whether a given regression line was significant or if significant differences existed when a given ANOVA design was applied to specific factors. We rather developed a quantitative and qualitative examination of the partition of variance at different levels of observation for different variables or combinations of variables.

\section{RESULTS}

\section{Morphometric parameters}

Principal component analysis (PCA) showed a low association of morphometric variables on a global level (all sites combined), although the first and second components explained $85 \%$ of the total variance. Only biomass and holdfast diameter showed a strong relationship at this level. The main utility of the PCA results was in detecting change in patterns of association of variables with scale, when PCA was repeated independently for zones and sites. Central zone stands (first 2 axes: $89 \%$ of variance) maintained a strong relationship between diameter and biomass, but for northern ones (first 2 axes: $84 \%$ of variance) the strongest association was found between diameter and number of stipes. Changes in association were also detected among sites. The strongest relationship in each case was: biomass with diameter for PT $193 \%$ of variance from first 2 axes), and also for QU ( $84 \%$ of variance) but with a lower association than for PT, biomass with number of stipes for ISM (83\% of variance), and diameter with number of stipes for CE ( $91 \%$ of variance). These results make evident that morphological features differ according to the scale level at which they are observed.

One-way analyses of variance for each morphometric variable classified by zone or site (Table 1) indicated that maximum plant length had the greatest contribution to variance, followed in a decreasing order by plant biomass, number of stipes, and holdfast diameter. Plants from central Chile stands attain a greater length and have a lower number of stipes than those from northern stands, and these were the main factors accounting for spatial variation in morphology. This last variable appeared homogeneous among stands, both at zone and site levels, and therefore is not useful for detecting variability and must be considered a conservative morphological measurement. On the other hand, the greater heterogeneity of the remaining variables was always associated with a zone effect, although differences were not constant since sometimes one zone and sometimes the other showed the higher mean value depending upon which variable was considered.

Table 1. Lessonia trabeculata. One-way analyses of variance for morphometric variables. Results obtained independently for zone and site are presented together for each variable

\begin{tabular}{|lrrrc|}
\hline Source & df & $\begin{array}{c}\text { Mean } \\
\text { square }\end{array}$ & F-ratio & $\mathrm{p}$ \\
\hline Maximum length & & & \\
Zone & 1 & 64915.8 & 54.33 & $<0.0001$ \\
Error & 194 & 1194.9 & & \\
Site & 3 & 25792.4 & 22.58 & $<0.0001$ \\
Error & 192 & 1142.4 & & \\
Plant biomass & & & & \\
Zone & 1 & $1.703 \cdot 10^{8}$ & 19.64 & $<0.0001$ \\
Error & 194 & $8.647 \cdot 10^{6}$ & & \\
Site & 3 & 84789438 & 10.22 & $<0.0001$ \\
Error & 192 & 8299597 & & \\
No. of stipes & & & & \\
Zone & 1 & 355.59 & 9.70 & 0.0021 \\
Error & 194 & 36.68 & & \\
Site & 3 & 193.70 & 5.40 & 0.0014 \\
Error & 192 & 35.89 & & \\
Holdfast diameter & & & \\
Zone & 1 & 31.20 & 0.57 & 0.4607 \\
Error & 194 & 55.10 & & \\
Site & 3 & 150.37 & 2.81 & 0.0407 \\
Error & 192 & 53.49 & & \\
& & & & \\
\hline
\end{tabular}


Table 2. Lessonia trabeculata. Multiple regression fitting results for plant biomass vs morphometric variables at global (all sites pooled) and zone levels (values in $\log _{10}$ ). Coefficients were significant in all cases $(p|>| t \mid]<0.01)$, but only sequential sums of squares are presented for comparison. Good relationships were obtained, but each fit and the relative contribution of variables (sequential sum of squares) were quite different in the different levels

\begin{tabular}{|lrrrr|}
\hline Source & df & $\begin{array}{c}\text { Sequential } \\
\text { mean square }\end{array}$ & $F$-ratio & $p$ \\
Global & & & & \\
No. of stipes & 1 & 6.9505 & 136.46 & $<0.0001$ \\
$\begin{array}{l}\text { Diameter } \\
\text { Max. length }\end{array}$ & 1 & 2.4855 & 48.80 & $<0.0001$ \\
Northern zone & 20.5202 & 402.88 & $<0.0001$ \\
No. of stipes & 1 & 11.8945 & 289.56 & $<0.0001$ \\
$\begin{array}{l}\text { Diameter } \\
\text { Max. length }\end{array}$ & 1 & 0.5196 & 12.65 & 0.0006 \\
Cenirai zone & & 2.5521 & 62.13 & $<0.0001$ \\
No. of stipes & 1 & 0.5659 & 16.92 & 0.0001 \\
$\begin{array}{l}\text { Diameter } \\
\text { Max. length }\end{array}$ & 1 & 2.4502 & 73.27 & $<0.0001$ \\
& 1 & 9.3369 & 279.22 & $<0.0001$ \\
\hline
\end{tabular}

The above results suggest that covariation in these morphological attributes is not predictable. For a complementary evaluation of their quantitative relationships we obtained linear equations for biomass prediction from morphometric measures by stepwise (forward selection of variables) and multiple regression for each observation level. These relationships are not presented here as the best predictors for each site but rather as model fitting results when all variables are taken into account. A global model combining all sites (adjusted $\mathrm{R}^{2}=0.75 ; F_{3.192}=196.05 ; \mathrm{p}<0.0001$ ) indicates that plant length is the major contributor to the explanation of variance (see Table 2 for global and zonal contributions of each variable). When zones were analyzed, models exhibited a better and similar fit, although differing in the explanation of variance. For central sites $\left(\mathrm{R}^{2}=0.79, F_{3,94}=123.14, \mathrm{p}<0.0001\right)$, plant length was the best contributor, while for northern sites $\left(R^{2}=\right.$ $\left.0.79, F_{3.94}=121.45, \mathrm{p}<0.0001\right)$ number of stipes was the best. Among sites, equations differ markedly (Table $3)$, and the corresponding models $\left(0.36<\mathrm{R}^{2}<0.91\right.$, $25.76<F_{3,45}<146.66, \mathrm{p}<0.0001$ for all sites) indicated that the relative importance of variables varied in a clearly site-dependent way. These results are consistent with the above statistical analysis.

On this basis, we performed a discriminant analysis for the whole set of morphometric variables, which indicated a fair segregation between northern and central Chile sites (Fig. 1), although no more than 70 to $80 \%$ of classification results were predicted by the model. Two of the 3 discriminant functions derived were significant, but the segregation was observed
Table 3. Lessonia trabeculata. Multiple regression fitting results for morphometric variables by site. All coefficients for each model were significant $(p|>| t \mid]<0.03)$, and likewise all regression models $\left(p<0.0001 ; 25.8<F_{3.45}<146.7\right)$. Sequential sums of squares are presented for contrasting relative contributions of variables among sites. The order of variables was previously determined by stepwise regression. Model coefficients are listed below each site name to the left of the respective variable, and intercept values and determination coefficients (adjusted for df) to the right of the site name

\begin{tabular}{|c|c|c|c|c|}
\hline Site & Source & $\begin{array}{c}\text { Sequential } \\
\text { mean square }\end{array}$ & $F$-ratio & $\mathrm{p}$ \\
\hline \multicolumn{5}{|c|}{$\mathrm{CE}_{1}-0.3476, \mathrm{R}^{2}(\mathrm{adj})=0.779}$. \\
\hline 0.7060 & No. of stipes & 6.4808 & 149.58 & $<0.0001$ \\
\hline 0.6856 & Diameter & 0.3009 & 6.94 & 0.0115 \\
\hline 0.9867 & Max. length & 0.6696 & 15.45 & 0.0003 \\
\hline \multicolumn{5}{|c|}{ ISM $,-1.6744, R^{2}$ (adj.) $=0.806$} \\
\hline 0.7256 & No. of stipes & 5.6996 & 150.33 & $<0.0001$ \\
\hline 0.3879 & Diameter & 0.2063 & 5.44 & 0.0242 \\
\hline 1.8021 & Max. length & 1.7801 & 46.95 & $<0.0001$ \\
\hline \multicolumn{5}{|c|}{ PT $,-1.6376, R^{2}(\operatorname{adj})=0.901}$. \\
\hline 0.2259 & No. of stipes & 0.1997 & 11.19 & 0.0017 \\
\hline 1.8199 & Diameter & 7.1068 & 398.36 & $<0.0001$ \\
\hline 1.2066 & Max. length & 0.5428 & 30.42 & $<0.0001$ \\
\hline \multicolumn{5}{|c|}{$\mathrm{QU}_{1}-2.5768, \mathrm{R}^{2}(\mathrm{adj})=0.607$} \\
\hline 0.2731 & No. of stipes & 1.0701 & 24.87 & $<0.0001$ \\
\hline 0.6725 & Diameter & 0.2522 & 5.86 & 0.0196 \\
\hline 2.3111 & Max. length & 2.0021 & 46.54 & $<0.0001$ \\
\hline
\end{tabular}

mainly in the first axis, which explained $88 \%$ of total variance. Although this analysis used site as a classification factor, individual stands appeared naturally grouped by zone, showing the good descriptive resolution of multivariate methods which account fairly for

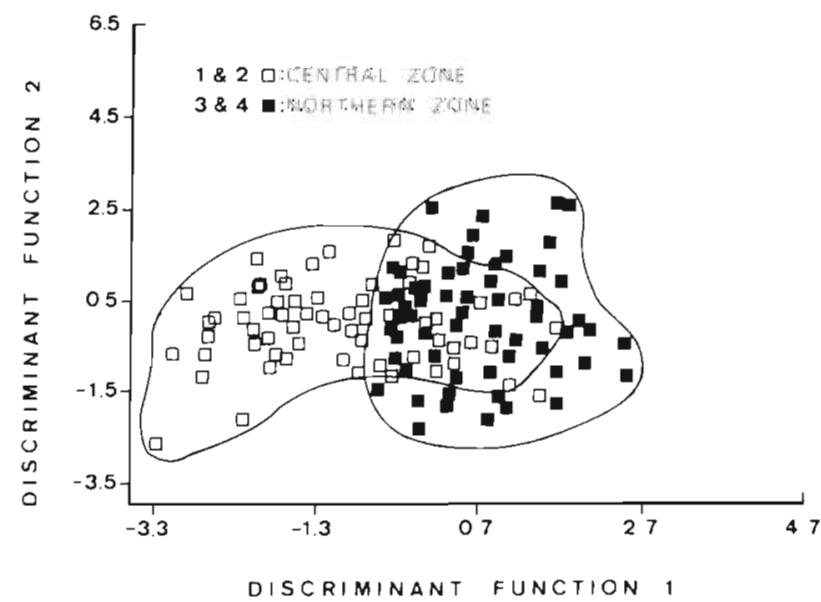

Fig. 1. Plot of first 2 functions of a discriminant analysis using site as classification factor, based on morphological observations in stands of Lessonia trabeculata. The first axis allowed a natural segregation of sites into 2 groups, corresponding to the study zones 
morphological variation among stands. No within-zone difference between stands was apparent, thus suggesting the importance of mesoscale physical factors as determinants of morphological features (namely subsuming local variations).

\section{Density estimates}

Evenness and density profiles generally showed a low, although significant, overall association ( $\mathrm{r}=0.67$, $p<0.0001, n=32$ ). At a site-specific level, patterns were clearly different. Fig. 2A shows that only QU (central) and ISM (north) exhibited a bathymetric trend in density, whereas PT and CE were relatively uniform. Fig. 2B shows that only $Q U$ exhibited variations in spatial evenness, with marked changes in density. The remaining sites were quite homogeneous throughout their depth range. Global evenness and density for sites (averaging all depth intervals) reflected the highest variability and standing stock for $\mathrm{QU}$ for both
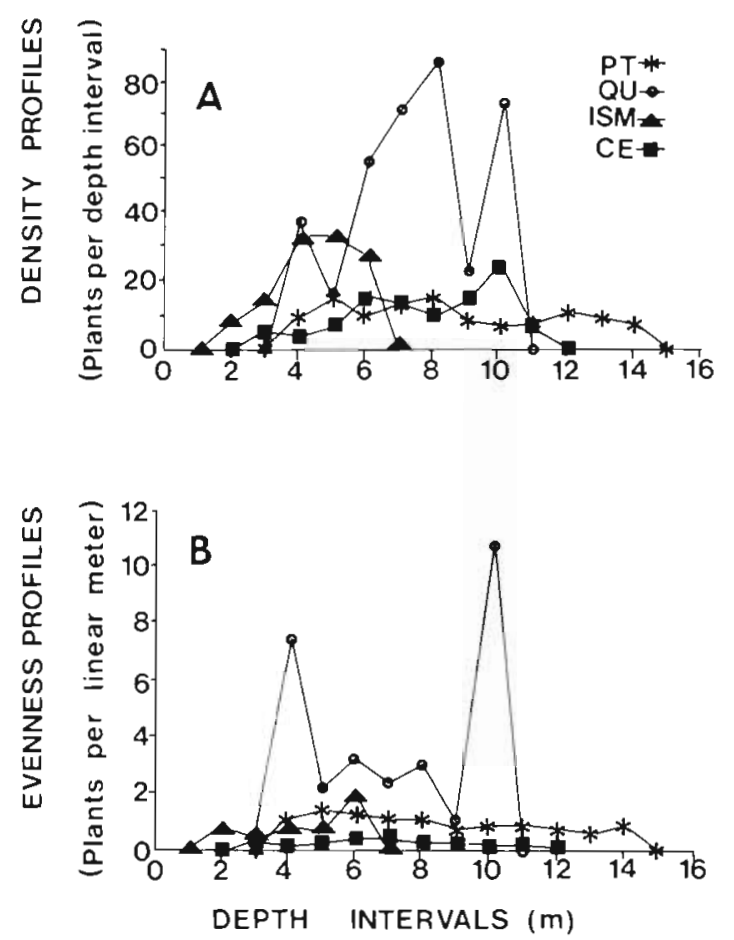

Fig. 2. Lessonia trabeculata. Density estimates per depth interval by sites. Both depth ranges and density levels exhibited marked variation among sites. Variances were roughly proportional to means for each site, and have been excluded for clarity. (A) Mean lineal density: ISM (north) and QU (central) showed approximately bell-shaped bathymetric profiles, while those for CE (north) and PT (central) were rather platykurtic. (B) Mean spatial evenness: a uniform bathymetric trend in density (see text for explanation) was evident for all sites but QU (central), which exhibited aggregation peaks at both extremes of its depth range

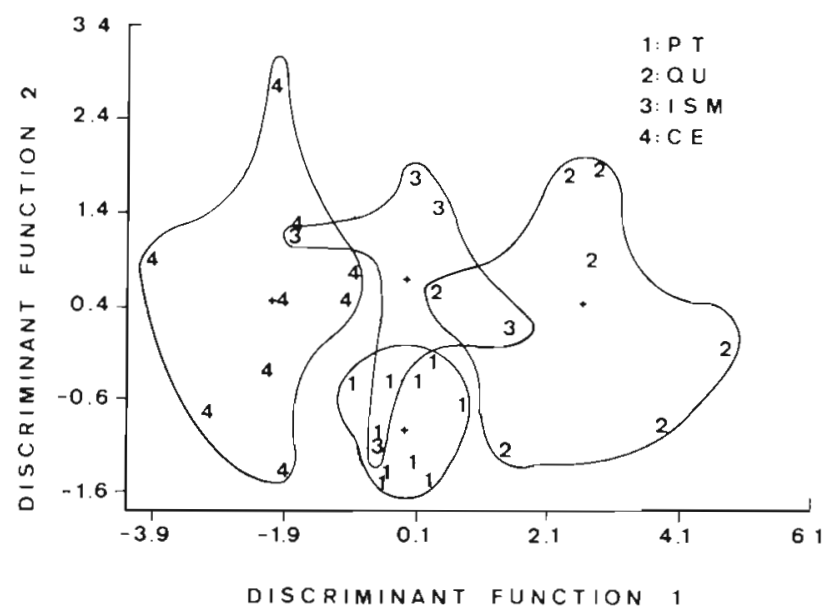

Fig. 3. Plot of first 2 discriminant functions for density and evenness estimates classified by site. In contrast to morphological traits (see Fig. 1), sites were fairly separated, except for a partial overlap of ISM with the rest of the sites

estimates $\left(8.90<F_{3,28}<14.79, \mathrm{p}<0.0003\right)$, as may be inferred from the profiles in Fig. 2. Variances for the remaining sites were not proportional in magnitude to their mean values, suggesting local determinants both for the shape and quantitative level of bathymetric profiles. No quantitative resemblance was apparent between northern or central Chile sites.

PCA did not show differences between zones for both estimates, even though the first component explained $80 \%$ of the variance in each case. Sites, on the other hand, were relatively well separated by discriminant analysis (Fig. 3). The first discriminant function explained almost $97 \%$ of the variance, showing lower resolution only for the ISM site, which partially overlapped with the remaining sites. These results contrast with the greater zone effect detected for morphometric measurements, stressing the lack of homogeneity among local stands which makes extrapolation from single stands of little value.

One-way ANOVAs both for density and evenness profiles showed similar results (Table 4). Site was the factor with great explanatory power for both estimates, and zone only introduced differences for evenness profiles. In this last case the differences may be mainly attributable to the distinctive features of QU.

\section{DISCUSSION}

The different numeric descriptors of morphology and density examined for Lessonia trabeculata showed important zone-specific and, often, site-specific variability, so the stands cannot be treated as a whole. Very few parameters are homogeneous enough, in terms of 
Table 4. Lessonia trabeculata. One-way analyses of variance for density and evenness estimates, with values classified independently by zone and site. Variation among stands exhibited mainly a site-specific component. and a single stand (QU) accounted for most of the quantitative differences

\begin{tabular}{|c|c|c|c|c|}
\hline Source & df & $\begin{array}{l}\text { Mean } \\
\text { square }\end{array}$ & $F$-ratio & $\mathrm{p}$ \\
\hline \multicolumn{5}{|c|}{ Density profiles } \\
\hline Zone & 1 & 964.60 & \multirow[t]{2}{*}{2.20} & \multirow[t]{2}{*}{0.1484} \\
\hline Error & 30 & 438.44 & & \\
\hline Site & 3 & 2885.12 & \multirow[t]{2}{*}{14.79} & \multirow[t]{2}{*}{$<0.0001$} \\
\hline Error & 28 & 195.09 & & \\
\hline \multicolumn{5}{|c|}{ Evenness profiles } \\
\hline Zone & 1 & 23.64 & \multirow[t]{2}{*}{5.87} & \multirow[t]{2}{*}{0.0216} \\
\hline Error & 30 & 4.03 & & \\
\hline Site & 3 & 23.49 & \multirow[t]{2}{*}{8.90} & \multirow[t]{2}{*}{0.0003} \\
\hline Error & 28 & 2.64 & & \\
\hline "QU sig & tly & ent (Sch & $p<0.0$ & \\
\hline
\end{tabular}

spatial variation, to be useful in formulating generalizations at an overall level (i.e. for an ecological 'characterization' of the species), since their variability and relationships are differentially scaled between site and zone levels. However, it would be premature to suggest some mechanistic explanation for these patterns, or to consider them as 'adaptations' to local conditions.

In general, variability in morphometric parameters, just as for evenness estimates, was more strongly associated with zones than with sites as regards explanations of variance. Only density profiles showed a slightly greater dependence on site, but this was mainly caused by the unusually high values found for the QU site, which translated to a disproportionate contribution to variance. Excepting QU, a remarkable qualitative feature of stands was the high spatial evenness in the distribution of plants among depth intervals. This evenness is likely related to biological rather than physical determinants, but this cannot be evaluated from this study.

Even though site-specific factors may be important. the fact that stands from a given zone show a similar pattern in their allometric growth would suggest that, at the species level, geographical or spatial classes of stands may be recognized in terms of their growth pattern and morphology. Each class, namely a cluster of stands, would be statistically defined by confidence regions related to, for example, numeric relationships for biomass prediction or responses to environmental factors or habitat constraints. However, these classes should not be defined from extrapolation of local scale results, nor on the basis of classification a priori, nor in an observer-dependent way. Schiel \& Foster (1986) proposed a similar approach, where stands would be classified into different types according to the relative importance of various physical and biotic factors at different spatial and temporal scales.

Despite differences in density and evenness of northern and central Chile stands, and that best predictive models for biomass involved a different combination or contribution of variables in each stand, the relationship among morphometric parameters of Lessonia trabeculata was rather conservative at the zone level. Hymanson et al. (1990) examined morphometric relationships in 4 stands of the kelp Pterygophora californica, and found strong site-specific components affecting predictive equations for age, although some significant overall relationship was also found. In our study, the covariation observed among morphological traits showed that specificity, at each level of resolution, is given by the kind and number of parameters included either in prediction or in pattern description on the basis of their explanatory power. At a given level (e.g. site), each stand exhibits variability patterns that cannot be extrapolated to other ones. Furthermore, just as pointed out for Pterygophora by Hymanson et al. (1990), even within stands the covariation among certain parameters may be non-significant. Nonetheless, the highly specific way in which different descriptors account for the total variance in single stands dilutes as they are aggregated into the higher level of zone. The influence of zone in the case of $L$. trabeculata is probably due to the sheltered features of the ISM and CE sites, with lower water motion and higher temperature than the central Chile sites. These have been shown to be important factors in determining differential algal morphology and abundance between localities (e.g. Dayton et al. 1984, Dayton 1985a, Schiel \& Foster 1986). Undoubtedly, biological factors such as herbivory may also be involved in producing such variation (e.g. Dayton 1985b, Vásquez 1991).

On the other hand, morphometric measurements for Lessonia trabeculata also reflect well-defined patterns at small spatial scales, and therefore they may be considered good descriptors for assessing local and geographical variation. Other studies (e.g. Hatcher 1989) have also shown differences in benthic community structure in a multiscale approach, depending upon environmental attributes like exposure and habitat topography.

Studies combining multivariate methods with analysis of variance (e.g. Hatcher 1989) may be helpful for discriminating patterns at different scales of observation. In this work variables were not properly scaled, but the observation point was held constant while varying the scale. This permitted the detection of changes in pattern as higher-scale signals are incorporated into the observations, redefining the data set (Allen \& Starr 1982). This approach may be profitable as initial obser- 
vations of possible habitat constraints or scale-dependent patterns for comparative studies of population or community structure. An identification of the scope of variability at each level of scale allows characterization of the structural properties of macroalgal stands, which in hierarchical terms may be termed its constraining envelope (O'Neill et al. 1989). If specific-level constraints are known, it might be possible to define a hierarchical framework for the analysis of population variation (Camus 1992), scaling structural properties across levels and relating them to the underlying biological processes.

Interestingly, the 2 sets of variables analyzed in this study varied in different ways with scale, pointing out that a change in the dimension of variability in a given set of parameters does not necessarily involve a change in their relationship. Fig. 4 shows the variance of parameters at different levels of observation, which define the scale of resolution within each parameter. Fig. 4A shows a decreasing trend in variance for density
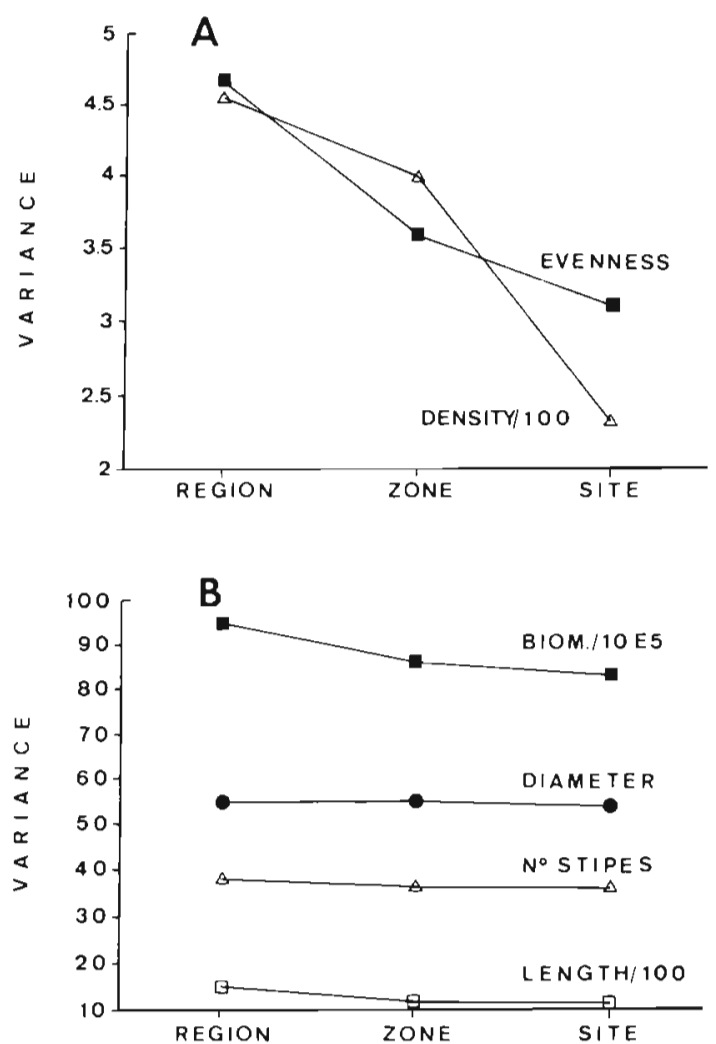

Fig. 4. Relation between variance magnitudes of variables and spatial scale. Some values were adjusted by correction factors for presentation. Region refers to overall values, which subsume zone and site levels. (A) Positive relation of variance of density estimates with scale. Despite this increasing trend, the relationship between both variables remained unaltered. (B) Insensitivity to scale of variance of morphometric parameters. Nevertheless, the suite of variables exhibited noticeable changes in their association across spatial levels estimates from higher to lower levels, but, as was indicated by multivariate analysis, there is no change in association between variables. Conversely, Fig. 4B shows the relative insensitivity of morphometric parameters with scale, while they markedly changed their association at each level. This fact suggests additional sources of complexity in the interpretation of this kind of pattern. Unless scale (or scaling) considerations are explicit, linear extrapolation to different levels of variation (e.g. see Wiens 1989) is not feasible if underlying non-linear relationships among variables exist.

At present, the only study characterizing the structure of northern and central Chile communities of Lessonia trabeculata is that of Villouta \& Santelices (1984). Some of their qualitative suggestions are mainly based on quantitative results from 1 or 2 localities, as are some generalizations on the utility of certain morphometric parameters for predicting other morphometric characters or plant biomass. As shown in the present work, this kind of statement could be spurious if between-site variance or site-dependent effects are not considered. If variability is ignored, generalizations based on assumptions of environmental homogeneity may rather represent oversimplistic views of structure and organization in a given ecological system (see Foster 1990).

Acknowledgements. We are grateful for financial support from Fundación Andes, Chile, to the first author, and grant FONDECYT $349 / 91$ to the second author. We sincerely appreciate the invaluable help by I. Kong (Antofagasta), who made possible field work at northern Chile. We also thank M. S. Foster for suggestions on the first draft of this manuscript, and 5 anonymous reviewers for useful corrections and comments. Field assistance by A. Palma, K. Fariña, E. Varas, G. Benavides, L. Fuentes, W. Cáceres, and 'el L'eri' is also acknowledged.

\section{LITERATURE CITED}

Allen, T F. H., Starr, T R. (1982), Hierarchy. Perspectives for ecological complexity. Univ. of Chicago Press, Chicago

Camus, P. A. (1992). Hierarchical analysis and its conceptual use in ecology. Rev. Chil. Hist. nat. 65: 287-296 (in Spanish)

Dayton, P. K. (1985a). Ecology of kelp communities. A. Rev. Ecol. Syst. 16: 215-245

Dayton, P. K. (1985b). The structure and regulation of some South American kelp communities. Ecol. Monogr. 55: $447-468$

Dayton, P. K., Currie, V., Gerrodette, T., Keller, D., Rosenthal, R., ven Tresca, D. (1984). Patch dynamics and stability of some California kelp communities. Ecol. Monogr. 54: 253-289

Foster, M. S. (1990). Organization of macroalgal assemblages in the Northeast Pacific: the assumption of homogeneity and the illusion of generality. Hydrobiologia 192: 21-33

Hatcher, A. (1989). Variation in the components of benthic community structure in a coastal lagoon as a function of spatial scale. Aust. J. mar Freshwat. Res. 40: 79-96 
Hymanson, Z. P., Reed, D. C., Foster, M. S., Carter, J. W. (1990). The validity of using morphological characteristics as predictors of age in the kelp Pterygophora californica (Laminariales. Phaeophyta). Mar. Ecol. Prog. Ser 59: 295-304

O'Neill, R. V., Johnson, A. R., King, A. W. (1989). A hierarchical framework for the analysis of scale. Landscape Ecol. 3 : 193-205

Rastetter, E. B., King, A. W., Cosby, B. J., Hornberger, G. M., O'Neill, R. V., Hobbie, J. E. (1992). Aggregating fine-scale ecological knowledge to model coarse-scale attributes of ecosystems. Ecol. Appl. 2: 55-70

Santelices, B. (1982). Bases biológicas para el manejo de Lessonia nigrescens (Phaeophyta; Laminariales) en Chile central. Monografías Biológicas (Chile) 2: 135-150

Santelices, B., Ojeda, F. P. (1984). Population dynamics of coastal forests of Macrocystis pyrifera in Puerto Toro, Isla Navarino, southern Chile. Mar. Ecol. Prog. Ser 24: $175-183$

This article was presented by J. E. Winter, Valdivia, Chile
Schiel, D. R., Foster, M. S. (1986). The structure of subtidal algal stands in temperate waters. Oceanogr mar. Biol. A. Rev. 24: 265-307

Statgraphics (1988). Users's guide-reference, 3rd edn. STS, Inc.

Vásquez, J. (1990). Comunidades submareales dominadas por macroalgas. Rev. Chil. Hist. nat. 63: 130-131

Vásquez, J. A. (1991). Variables morfométricas y relaciones morfológicas de Lessonia trabeculata Villouta \& Santelices, 1986, en una población submareal del norte de Chile. Rev. Chil. Hist. nat. 64: 271-280

Villouta, E., Santelices, B. (1984). Estructura de la comunidad submareal de Lessonia (Phaeophyta, Laminariales) en Chile norte y central. Rev. Chil. Hist. nat. 57: 111-122

Villouta, E., Santelices, B. (1986). Lessonia trabeculata sp. nov. (Laminariales, Phaeophyta), a new kelp from Chile. Phycologia 25: 81-86

Wiens, J. A. (1989). Spatial scaling in ecology. Funct. Ecol. 3: 385-397

Manuscript first received: August 24, 1991

Revised version accepted: September 29,1992 